Yongguang Luo, Weifeng Zhang, Jing Li*, Libo Zhang*, Jingtian Zou, Jinming Hu, Lifeng Yang, Yunhao Xi and Tianqi Liao

\title{
Optimization of uranium removal from uranium plant wastewater by response surface methodology (RSM)
}

https://doi.org/10.1515/gps-2019-0050

Received April 01, 2019; accepted May 28, 2019.

Abstract: Uranium plant wastewater was treated in laboratory scale experiments by employing zero valent iron powder. Batch experiments conducted by the response surface methodology (RSM) proved significant decrease in concentrations of uranium due to a decrease in an oxidation-reduction potential and an increase in $\mathrm{pH}$ relative to an application of zero valent iron powder. Results indicated that it is effective on the removal of uranium from uranium plant wastewater with the uranium concentration of $2772.23 \mu \mathrm{g} / \mathrm{L}$ due to the adding of zero valent iron powder. it was found that the scope of $\mathrm{pH}$ is widely from

\footnotetext{
* Corresponding authors: Jing Li and Libo Zhang, Faculty of Metallurgical and Energy Engineering, Kunming University of Science and Technology, Kunming, Yunnan 650093, China; Kunming Key Laboratory of Special Metallurgy, Kunming, Yunnan 650093, China; Key Laboratory of Unconventional Metallurgy, Ministry of Education, Kunming, Yunnan 650093, China; Yunnan Provincial Key Laboratory of Intensification Metallurgy, Kunming, Yunnan 650093, China; State Key Laboratory of Complex Nonferrous Metal Resources Clean Utilization, Kunming University of Science and Technology, Kunming, Yunnan 650093, China; Tel: +8687165174756; e-mail: lijingkind@163.com, zhanglibopaper@126.com

Yongguang Luo, Faculty of Metallurgical and Energy Engineering, Kunming University of Science and Technology, Kunming, Yunnan 650093, China; Yunnan Chihong Zn\&Ge CO., LTD, Qujing, Yunnan 655011, China
}

Weifeng Zhang, Faculty of Metallurgical and Energy Engineering, Kunming University of Science and Technology, Kunming, Yunnan 650093, China

Jingtian Zou, Yunhao Xi and Tianqi Liao, Faculty of Metallurgical and Energy Engineering, Kunming University of Science and Technology, Kunming, Yunnan 650093, China; Kunming Key Laboratory of Special Metallurgy, Kunming, Yunnan 650093, China; Key Laboratory of Unconventional Metallurgy, Ministry of Education, Kunming, Yunnan 650093, China; Yunnan Provincial Key Laboratory of Intensification Metallurgy, Kunming, Yunnan 650093, China; State Key Laboratory of Complex Nonferrous Metal Resources Clean Utilization, Kunming University of Science and Technology, Kunming, Yunnan 650093, China

Jinming Hu and Lifeng Yang, Nuclear group two seven two uranium industry limited liability company, Hengyang, Hunan 421000, China
3 to 5 from the experimental data obtained in this study. The predicted model obtained from response surface methodology is in accordance with experimental results.

Keywords: response surface methodology; uranium plant wastewater; uranium removal

\section{Introduction}

Processing of uranium ores for nuclear power production has resulted in plenty of radioactive dust generation with serious impact on the environment [1-5]. Radionuclides such as uranium and its compounds deserve special attention due to their high heavy-metal toxicity and radioactivity [6,7]. The toxicity of uranium (VI) ions in the form of $\mathrm{UO}_{2}^{2+}$, existed in uranium plant wastewater systems, even at micro level, has been a public health issue over the years [8]. So, the study on removal of uranium from wastewater is significant. To be effective in the long run, any remediation technique for uranium must be target on both mobile aqueous uranium (VI) precipitates and uranium (VI) species which may be longstanding sources [9].

The uranium content of uranium plant wastewater used as study object in this paper is $2772.23 \mu \mathrm{g} / \mathrm{L}$. It is 55 times more than the emission value of $50 \mu \mathrm{g} / \mathrm{L}$ proposed in the Regulations for radiation protection for uranium processing and fuel fabrication facility (EJ1056-2005) [10]. Therefore, affordable, efficient and applicable technology is necessary to reduce the health risk by mitigating or eliminating the uranium removal from the uranium plant wastewater. To improve removal efficiency of uranium, optimization method was used to optimize the operation conditions such as $\mathrm{pH}$, dosage of zero valent iron powder, reaction time. Zero valent iron was used to reduce soluble uranium (VI) aqueous species to undissolved uranium (IV) sediments in this paper.

Response surface methodology (RSM), one of the most economical and practical solutions to evaluate single and combinatorial factors of experiment variables which lead to output responses [11-13]. could be utilized to accomplish 
the real design of experiments methods. Due to application of the RSM, less time consumption and fewer tests are consumed compared with actual experimental study $[14,15]$. The results of RSM analysis would provide the best system performance for the entire optimization set $[16,17]$. In this study, RSM was employed to study the influence of solution $\mathrm{pH}$, reaction time and dosage of zero valent iron on removal efficiency of uranium. In the course of the study, inductively coupled plasma mass spectrometry (ICPMS) was used to detect the uranium content of solution. Five measurements were averaged to minimize the error. The detection range of ICP-MS is between $10^{-9}-1 \mathrm{mg} / \mathrm{L}$ with relative standard deviation of less than $5 \%$.

Response surface methodology (RSM) was employed to optimize the uranium removal process from uranium plant wastewater with the aim of uranium contents less than $50 \mu \mathrm{g} / \mathrm{L}$. RSM is important for the process under study, because it has been used in empirical studies to assess the impact of input parameters on a set of dependent variables $[18,19]$. Three variables of $\mathrm{pH}$, dosage of zero valent iron powder and reaction time have been performed. Each treated wastewater sample has been characterized in uranium removal efficiency terms. The RSM was applied to determine the best uranium removal process conditions by using $\mathrm{pH}$, dosage of zero valent iron powder and reaction time data as dependent variables. The optimum combination predicted by RSM was obtained through experiments, whereby almost complete uranium removal with uranium removal efficiency of $99.66 \%$, by using amount of $3 \mathrm{~g} / \mathrm{L}$ zero valent iron, 52.5 min reaction time and $\mathrm{pH}$ of 5 .

\section{Experimental procedure and design}

\subsection{Experimental procedure}

The uranium plant wastewater used in this paper was obtained from purification processing with the uranium concentration of $2772.23 \mu \mathrm{g} / \mathrm{L}$, the $\mathrm{pH}$ value of 8.69 . The zero-valent iron was of analytical pure grade with above $98 \%$ purity. Extraction raffinate with uranium concentration of $2984.1 \mu \mathrm{g} / \mathrm{L}$, which $\mathrm{pH}$ value was 0.12 , was used to pretreat $\mathrm{pH}$ adjustment of wastewater.

\subsection{Experimental design}

Many research workers have done lots of work on enhancing uranium removal efficiency from uranium-containing wastewater so far [20]. Uranium concentration of $50 \mu \mathrm{g} / \mathrm{L}$ is allowed to discharge instead of $300 \mu \mathrm{g} / \mathrm{L}$ mentioned in the Integrated Wastewater Discharge Standard (GB8798-1996) [21], according to the Regulations for radiation protection for uranium processing and fuel fabrication facility (EJ10562005). Therefore, an innovative statistical approach with high uranium removal efficiency is imperative.

The RSM establishes a set of mathematical models which represents the response surfaces of the measured property (uranium removal efficiency, in this study) through a given set of input variables $(\mathrm{pH}$, dosage of zero valent iron powder, in that case, reaction time) In a particular area of interest. In this study, RSM was used to find the maximum of a particular response (maximum uranium removal efficiency) determining the input variables $(\mathrm{pH}$, dosage of zero valent iron powder or reaction time) that produced the maximum response, and so, the optimum uranium removal technological conditions.

\section{Results and discussion}

The uranium removal efficiency obtained from RSM experiments are listed in Table 1, along with their units,

Table 1: Uranium removal experimental design used in RSM studies by using process variables showing observed values of uranium removal efficiency.

\begin{tabular}{|c|c|c|c|c|}
\hline \multirow[t]{3}{*}{ Run } & \multicolumn{3}{|c|}{ Variables } & \multirow{3}{*}{$\begin{array}{c}\text { Response } \\
\text { Uranium removal } \\
\text { efficiency (\%) } \\
\text { Y }\end{array}$} \\
\hline & $\begin{array}{l}\mathrm{pH} \\
(-)\end{array}$ & $\begin{array}{l}\text { Reaction } \\
\text { time (min) }\end{array}$ & $\begin{array}{l}\text { Dosage of zero-valent } \\
\text { iron powder (g) }\end{array}$ & \\
\hline & & & & \\
\hline 1 & 3 & 30 & 0.4 & 92.26 \\
\hline 2 & 5 & 52.5 & 0.6 & 98.50 \\
\hline 3 & 8.36 & 52.5 & 0.6 & 51.42 \\
\hline 4 & 5 & 52.5 & 0.26 & 99.20 \\
\hline 5 & 5 & 52.5 & 0.94 & 99.63 \\
\hline 6 & 5 & 52.5 & 0.6 & 99.45 \\
\hline 7 & 7 & 75 & 0.4 & 88.09 \\
\hline 8 & 3 & 75 & 0.4 & 98.54 \\
\hline 9 & 5 & 52.5 & 0.6 & 99.66 \\
\hline 10 & 5 & 14.66 & 0.6 & 99.21 \\
\hline 11 & 3 & 75 & 0.8 & 99.46 \\
\hline 12 & 5 & 52.5 & 0.6 & 97.70 \\
\hline 13 & 5 & 52.5 & 0.6 & 98.59 \\
\hline 14 & 1.64 & 52.5 & 0.6 & 98.46 \\
\hline 15 & 3 & 30 & 0.8 & 98.17 \\
\hline 16 & 7 & 30 & 0.8 & 90.04 \\
\hline 17 & 5 & 90.34 & 0.8 & 99.50 \\
\hline 18 & 5 & 52.5 & 0.8 & 99.22 \\
\hline 19 & 7 & 75 & 0.8 & 87.18 \\
\hline 20 & 7 & 30 & 0.4 & 89.04 \\
\hline
\end{tabular}


according to RSM design. The entire set of runs is shown in Table 1. The RSM has the abilities of estimation and prediction abilities to build effective models with maximum responses. Besides that, a set of mathematical models are established which represent the response surfaces of uranium removal efficiency by a given set of input variables $(\mathrm{pH}$, reaction time and dosage of zerovalent iron powder, in that case) In a particular area of interest. The multiple regression coefficients obtained by the second-order polynomial model for predicting uranium removal efficiency by using the least squares technique, are summarized in Eq. 1.

$$
\begin{aligned}
Y= & 98.79-8.29 A+0.31 B+0.56 C-1.42 A B-0.84 A C \\
& -0.86 B C-8.02 A^{2}+0.61 B^{2}+0.64 C^{2}
\end{aligned}
$$

The $\mathrm{F}$ test analysis of variance (ANOVA) was used to evaluate the statistical significance of the model equation. ANOVA evaluations of the model, given in Table 2, suggest that the experiments could be described by this model. The significance of each coefficient was determined by P-value and F-value. As shown in Table 2, the prob > F-values for uranium removal efficiency is lower than 0.05, which indicating that quadratic models were significant [22]. The $p$ values of both responses are less than 0.1, which indicates that lack of fit for the model was significant. The normal probability of the residuals $\left(\mathrm{R}^{2}=0.8542\right)$ indicated that there was no anomaly in the adopted methodology. The "lack of fit test" compares residuals to "pure errors" from repeated experimental design points. Adequate accuracy in measuring SNR and SNR greater than 4 is desirable. The ratio of 9.899 indicated a sufficient signal. The model is significant to the whole process, due to high value of adequate precision.

In the model ANOVA, the correlation coefficient $\mathrm{R}^{2}$ of the quadratic regression equation was 0.8542 , which indicated model fit the actual situation very well. F-value

Table 2: ANOVA analysis for responses $Y$ [uranium removal efficiency (\%)].

\begin{tabular}{lrrrrr}
\hline Source & $\begin{array}{r}\text { Sum of } \\
\text { squares }\end{array}$ & $\begin{array}{r}\text { DF } \\
\text { square }\end{array}$ & $\begin{array}{r}\text { Mean } \\
\text { squalue }\end{array}$ & Prob $>$ F \\
\hline For Y & & & & & \\
Model & 1951.82 & 9 & 216.87 & 6.51 & 0.0036 Significant \\
Residual & 333.26 & 10 & 33.33 & & \\
Lack of fit & 333.26 & 5 & 66.12 & $124.03<0.0001$ Significant \\
Pure error & 2.67 & 5 & 0.53 & & \\
$R^{2}=0.8542$ & & & & & \\
Pred R-Squared $=-0.1013$ & & & & \\
Adeq Precision $=9.899$ & & &
\end{tabular}

of 6.51 implies the significance of the models. Because of noise there is only a $0.36 \%$ chance of such a large "model f value". The values of "Prob > F" are less than 0.05 that indicate the model term is significant. On this occasion, $\mathrm{A}^{2}$ and $\mathrm{A}$ are significant model terms. A negative "Pred R-Squared" with value of -0.1013 indicates the overall mean is better at predicting responses than the current model. "Adeq Precision" is desirable for signal to noise ratio measurements. In this paper, the ratio of uranium removal experiments is 9.899 , a ratio greater than 4 , that indicates an adequate signal. This model could be used to navigate the design space.

The predicted and actual uranium removal efficiency were plotted in Figure 1. As Figure 1 shown, the response predicted values slightly deviated from experimental data. The quadratic model curves are shown in Figure 2 with selected process variables $(\mathrm{pH}$, reaction time, dosage of zero-valent iron powder) kept at a constant level and the other two varying with the experimental ranges.

This method with the maximum U-removal efficiency of 99.66, has shown high effect on uranium removal, occurring from $2772.23 \mu \mathrm{g} / \mathrm{L}$ uranium plant wastewater within $0.40-0.80 \mathrm{~g}$ dosage of zero valent of iron powder, the 30-75 min reaction time, for wastewater with $\mathrm{pH}$ 3-7.

As Figure 2 shown, firstly, the uranium removal efficiency increased gradually with increasing $\mathrm{pH}$ value and then became decreasing sharply when $\mathrm{pH}$ value reaching to 5. The experiments results indicated that mildly acidic $\mathrm{pH}(\mathrm{pH} 3-5)$ was suitable for the removal of uranium. In the weak acid, uranium exists as $\mathrm{UO}_{2}^{2+}$ which was easy to be reduced by zero valent iron to produce uranyl hydroxide precipitation by hydrolysis for higher uranium removal efficiency. But because of amphoteric properties of uranyl hydroxide, where the $\mathrm{pH}$ is close to neutral or alkaline, uranyl hydroxide precipitation

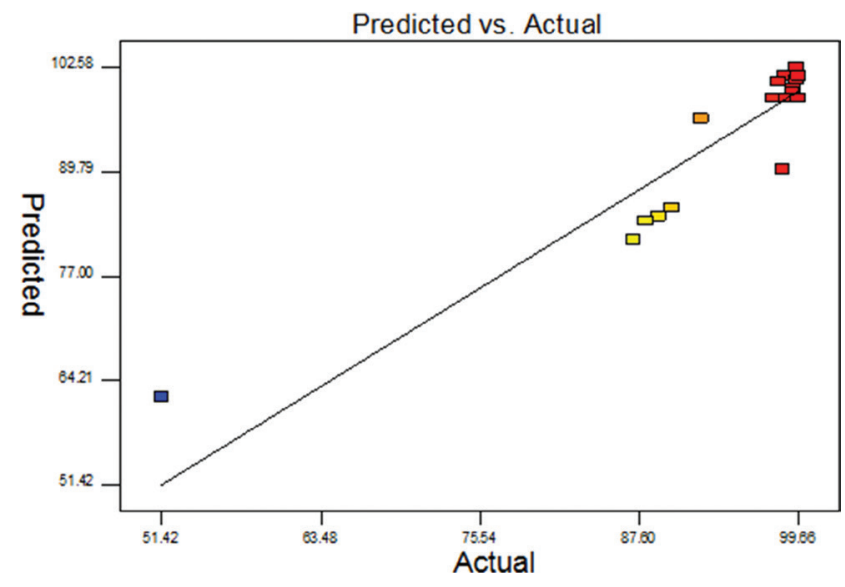

Figure 1: Predicted response vs. actual response. 


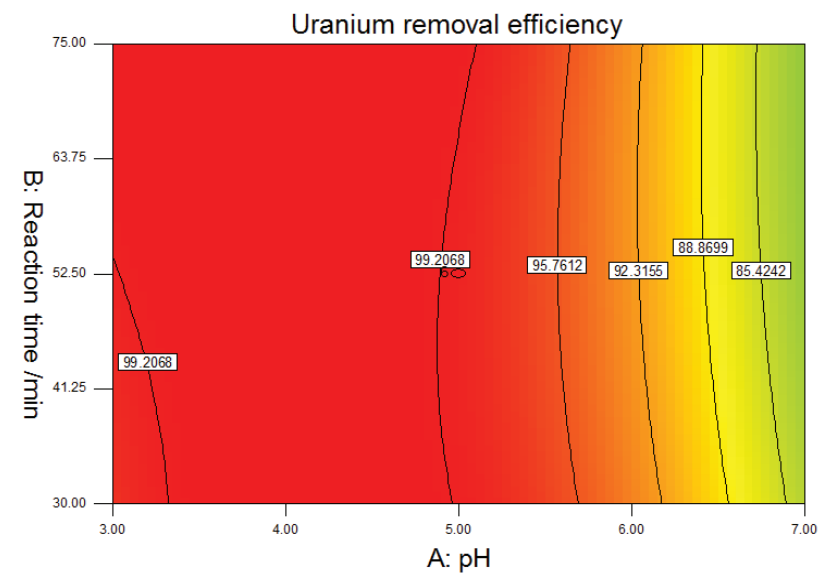

Actual Factor C: Dosage of zero-valent iron powder $=0.6 \mathrm{~g}$ (a) $\mathrm{AB}$

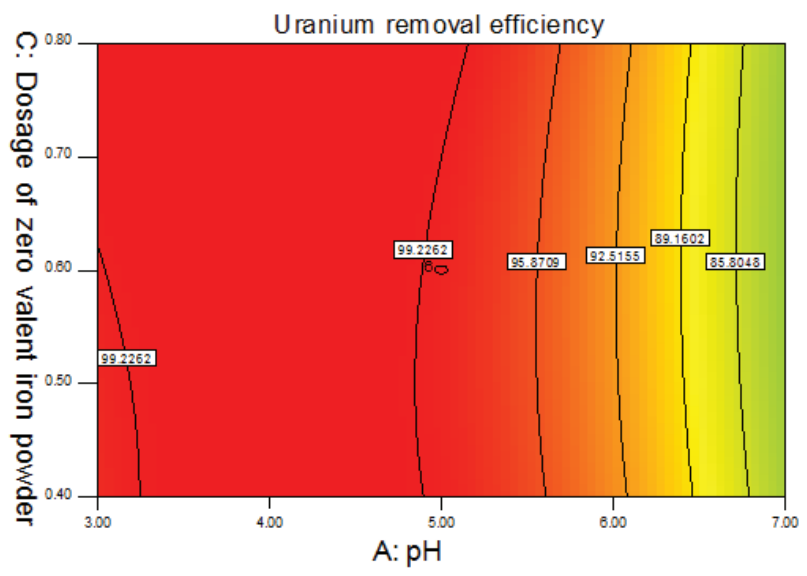

Actual Factor B: Reaction time $=52.5 \mathrm{~min}$

(b) $\mathrm{AC}$

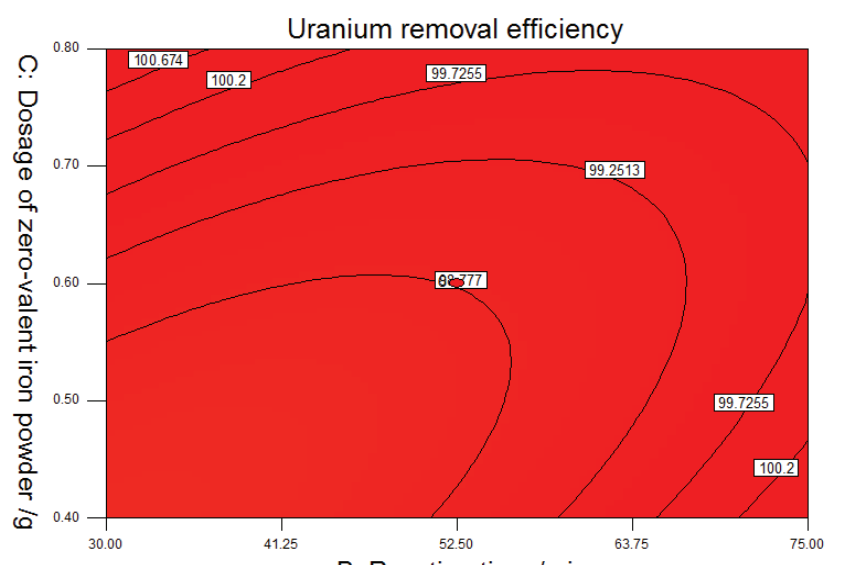

B: Reaction time /min

Actual Factor A: $\mathrm{pH}=5$

(c) $\mathrm{BC}$

Figure 2: The response surface diagram of the impact of $\mathrm{pH}$, reaction time and dosage of zero-valent iron on uranium removal efficiency.
Table 3: Predicted value vs. validation experiment value.

\begin{tabular}{ccccc}
\hline pH & Reaction & Dosage of & & Uranium removal efficiency (\%) \\
A & $\begin{array}{c}\text { time } \\
\text { B (min) }\end{array}$ & $\begin{array}{c}\text { zero-valent of } \\
\text { iron C (g) }\end{array}$ & Predicted value & Experiment value \\
\hline 5 & 52.5 & 0.6 & 98.79 & 99.44 \\
\hline
\end{tabular}

would transfer to the form of $\mathrm{UO}_{4}^{2-}$ and $\mathrm{U}_{2} \mathrm{O}_{7}^{2-}$ plasma. In the alkaline solution, uranium can inhibit the reduction and precipitation of uranium by zero valent iron. The uranium is returned to the solution that leads to the uranium removal efficiency decreased sharply. Secondly, with the extension of reaction time, the effect of uranium removal becomes better, and then after $52.5 \mathrm{~min}$ is steady. That because with the longer reaction time, the contact chance of zero valent iron and uranium (VI) is better, which would promote the combination with iron hydroxide flocculation body and uranium acyl. Better combination of flocs of iron hydroxide and uranium acyl would be positive to uranium removal. When the reaction reaches equilibrium, the longer reaction time has no effect on the reaction of uranium removal. Longer reaction time makes no difference on the removal of uranium. Thirdly, with increase of dosage of iron powder, the effect of uranium removal becomes better, and then over excess of $0.6 \mathrm{~g}$ is steady. More iron powder dosage, more uranium removal. When the content of uranium in the wastewater is low enough, removing uranium reaction would stop. Therefore, more iron powder has no effect on uranium removal reaction. As Table 1 and Figure 2 shown, the maximum uranium removal efficiency of $99.66 \%$ was obtained in the optimum condition. The optimum conditions are $\mathrm{pH}$ of 5, dosage of zero valent iron of $0.6 \mathrm{~g}$, reaction time of $52.5 \mathrm{~min}$. The experiment verified the accuracy of the mathematical model generated by the RSM design when only $0.65 \%$ residual error was left in the given optimal medium setting. The optimized process parameters were shown in Table 3.

\section{Conclusions}

Nitric acid was replaced by extraction raffinate for $\mathrm{pH}$ adjustment in the process, which is not only have a good result on uranium removal, but also enhancing resources comprehensive utilization.

It is an effective method to remove uranium from uranium plant wastewater by using zero valent powder. 
The maximum removal rate of uranium was 99.66\% occurring from $2772.23 \mu \mathrm{g} / \mathrm{L}$ uranium plant wastewater with $0.6 \mathrm{~g}$ dosage of zero valent of iron powder, $52.5 \mathrm{~min}$ reaction time, for wastewater with $\mathrm{pH} 5$.

The maximum removal efficiency of uranium obtained in optimum condition was $98.79 \%$, which is good agreement with experiment one of $99.44 \%$ with $0.65 \%$ residual.

Acknowledgments: All the Authors are grateful for the Yunnan Provincial Science and technology key project (NO. 2017FA026), financial supports by the National Natural Science Foundation of China (No. 51404115), Kunming Key Laboratory of Special Metallurgy, and Academician Workstation of Advanced Preparation of Superhard Materials Field.

\section{References}

[1] Xie Y., Chen C.L., Ren X.M., Wang X.X., Wang H.Y., Wang X.K., Emerging natural and tailored materials for uraniumcontaminated water treatment and environmental remediation. Prog. Mater. Sci., 2019, 103, 180-234.

[2] Choudhary S., Sar P., Characterization of a metal resistant Pseudomonas $\mathrm{sp}$. isolated from uranium mine for its potential in heavy metal $\mathrm{Cii}^{2+}, \mathrm{Co}^{2+}, \mathrm{Cu}^{2+}$, and $\mathrm{Cd}^{2+}$ ) sequestration. Bioresource Technol., 2009, 100, 2482-2492.

[3] Pereira W.D., Kelecom A.G.A.C., da Silva A.X., do Carmo A.S., Py D.D., Assessment of uranium release to the environment from a disabled uranium mine in Brazil. J. Environ. Radioactiv., 2018, 188, 18-22.

[4] Torkabad M.G., Keshtkar A.R., Safdari S.J., Selective concentration of uranium from bioleach liquor of lowgrade uranium ore by nanofiltration process. Hydrometallurgy, 2018, 178, 106-115.

[5] Kazy S.K., D'Souza S.F., Sar P., Uranium and thorium sequestration by a Pseudomonas sp.: mechanism and chemical characterization. J. Hazard. Mater., 2009, 163, 65-72.

[6] Omidi M.H., Azad F.N., Ghaedi M., Asfaram A., Azqhandi M.H.A., Tayebi L., Synthesis and characterization of Au-NPs supported on carbon nanotubes: Application for the ultrasound assisted removal of radioactive $\mathrm{UO}_{2}{ }^{2+}$ ions following complexation with Arsenazo III: Spectrophotometric detection, optimization, isotherm and kinetic study. J. Colloid. Interf. Sci., 2017, 504, 68-77.

[7] Zou W., Zhao L., Han R., Removal of Uranium (VI) by Fixed Bed Ion-exchange Column Using Natural Zeolite Coated with Manganese Oxide. Chin. J. Chem. Eng., 2009, 17, 585-593.
[8] Han R., Zou W., Wang Y., Zhu L., Removal of uranium (VI) from aqueous solutions by manganese oxide coated zeolite: discussion of adsorption isotherms and $\mathrm{pH}$ effect. J. Environ. Radioactiv., 2007, 93, 127-143.

[9] Noubactep C., Schöner A., Meinrath G., Mechanism of uranium removal from the aqueous solution by elemental iron. J. Hazard. Mater., 2006, B132, 202-212.

[10] Regulations for radiation protection for uranium processing and fuel fabrication facility. EJ1056-2005, China Commission of Science Technology and Industry for National Defense, 2005.

[11] Taghipour T., Karimipour G., Ghaedi M., Asfaram A., Mild synthesis of a $\mathrm{Zn}$ (II) metal organic polymer and its hybrid with activated carbon: Application as antibacterial agent and in water treatment by using sonochemistry: Optimization, kinetic and isotherm study. Ultrason. Sonochem., 2018, 41, 389-396.

[12] Asghar A., Abdul Raman A.A., Daud W.M., A comparison of central composite design and Taguchi method for optimizing Fenton process. Sci. World J., 2014, 4, 1-14.

[13] Asfaram A., Ghaedi M., Dashtian K., Ghezelbash G.R., Preparation and Characterization of $\mathrm{Mn}_{0.4} \mathrm{Zn}_{0.6} \mathrm{Fe}_{2} \mathrm{O}_{4} \quad$ Nanoparticles Supported on Dead Cells of Yarrowia lipolytica as a Novel and Efficient Adsorbent/Biosorbent Composite for the Removal of Azo Food Dyes: Central Composite Design Optimization Study. ACS Sustain. Chem. Eng., 2018, 6, 4549-4563.

[14] Dastkhoon M., Ghaedi M., Asfaram A., Goudarzi A., Mohammadi S.M., Wang S.B., Improved adsorption performance of nanostructured composite by ultrasonic wave: Optimization through response surface methodology, isotherm and kinetic studies. Ultrason. Sonochem., 2017, 37, 94-105.

[15] Ma L., Han Y., Sun K., Lu J., Ding J., Optimization of acidified oil esterification catalyzed by sulfonated cation exchange resin using response surface methodology. Energy Convers. Manage., 2015, 98, 46-53.

[16] Bezerra M.A., Santelli R.E., Oliveira E.P., Villar L.S., Escaleir L.A., Response surface methodology (RSM) as a tool for optimization in analytical chemistry. Talanta, 2008, 76, 965-977.

[17] Awad O.I., Mamata R., Alic O.M., Azmia W.H., Kadirgamaa K., Yusria I.M., et al., Response surface methodology (RSM) based multi-objective optimization of fusel oil-gasoline blends at different water content in SI engine. Energ. Convers. Manage., 2017, 150, 222-241.

[18] Fernandez C., Verné E., Vogel J., Carl G., Optimisation of the synthesis of glass-ceramic matrix biocomposites by the “response surface methodology". J. Eur. Ceram. Soc., 2003, 23, 1031-1038.

[19] Camacho L.M., Deng S.G., Parra R.R., Uranium removal from groundwater by natural clinoptilolite zeolite: Effects of $\mathrm{pH}$ and initial feed concentration. J. Hazard. Mater., 2010, 175, 393-398. 
[20] Dickinson M., Scott T.B., The application of zero-valent iron nanoparticles for the remediation of a uranium-contaminated waste effluent. J. Hazard. Mater., 2010, 178, 171-179.

[21] Integrated Wastewater discharge Standard, GB8798-1996, National standard of the People's Republic of China, 1998.
[22] Verma P., Agrawal U.S., Sharma A.K., Sarkar B.C., Sharma H.K., Optimization of process parameters for the development of a cheese analogue from pigeon pea (Cajanus cajan) and soy milk using response surface methodology. Int. J. Dairy Technol., 2005, 58, 51-58. 